Professor Emérito da Escola de

Comunicações e Artes da USP.

\title{
UM PROFESSOR DE MATEMÁTICA NA ECA
}

Mesmo na era digital e virtual, a educação humanística continua como centro na relação Professor-Aluno

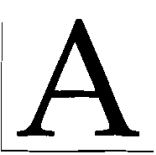

História registra que, no antigo Império Romano, ano 25 a.C., os senadores que prestavam relevantes serviços ao Império adquiriam o direito de viver na cidade chamada Augusta Mérita, construída por Augusto - primeiro imperador romano - e eleita como local-prêmio para receber tais senadores.

Augusta Mérita foi considerada uma das obras-primas do século de Augusto nome que se dá ao século mais brilhante da história de Roma. Hoje, esta mesma cidade, que está situada na Espanha, entre Salamanca e Santiago de Compostela, é denominada simplesmente Mérita, trazendo, ainda, traços indeléveis das clássicas construções romanas (teatros, salões, pontes, arquiteturas diversas de recepção e outras edificações), que retratam a cida- de-éden para os eméritos senadores responsáveis pelas causas nobres da época.

Neste prêmio que ora recebo de emérito, ao invés de senador a palavra utilizada é Professor, e isto deixa-me felicíssimo, porque ser Professor, meus amigos, é muito mais do que ter uma profissão. Na verdade, o Professor é um ser humano especial no exercício de vida, na transmissão de conhecimentos para outro ser humano. Desta forma, todo Professor é um educador na concepção multiabrangente da paidéia de Platão, na antiga Grécia - berço da Civilização Ocidental -, ao ressaltar ser o Professor o responsável direto pela própria formação do ser humano.

$\mathrm{Na}$ linguagem moderna, em tempo de era digital e das avançadas tecnologias da informação, o Professor continua

1. Discurso proferido pelo Prof. Dr. Osvaldo Sangiorgi na cerimônia pública de outorga do Título de Professor Emérito, pela Escola de Comunicações e Artes da Universidade de São Paulo, em 14 de dezembro de 2000. 
sendo o centro de gravidade de qualquer sistema educacional, mesmo que esse sistema transite numa faixa virtual, tão comum nos dias atuais.

Um exemplo edificante e oportuno entre os muitos que o Brasil possui - do que é ser Professor, está, no momento, na pessoa de Miguel Reale, que acaba de completar 90 anos de atividades ininterruptas nas áreas de Educação, da Cultura ampla e irrestrita, da Filosofia e da área Jurídica, da qual é figura proeminente, internacionalmente conhecida.

Homenageado há pouco pela Universidade de São Paulo, da qual foi seu Magnífico Reitor, por duas vezes, disse o nosso excelso referencial Professor Miguel Reale: "A presença mais importante aqui é a dos meus ex-alunos que representam 40 anos de trabalho; para eles sempre forneci um ensino formativo e não apenas dar-lhes informações e mais informações." A propósito dessa sábia sentença, destaca-se o importante fato de as pessoas estarem diariamente recebendo uma carga exagerada de informações (pela imprensa, rádio, televisão e de toda a hipermídia gerada no ciberespaço), num tempo em que o cérebro é incapaz de processá-las. Esse massacre contínuo de informações provoca a chamada síndrome da fadiga por informação, que produz sintomas físicos e psicológicos, para não dizer um estresse que impossibilita o cidadão de tomar decisões, adiando-as constantemente.

\section{PROFESSOR E ESCOLA VIRTUAL}

$\mathrm{Na}$ ordem do dia, têm-se ainda as Escolas Virtuais, Universidades Virtuais, que serão sempre bem-vindas, não só por apresentarem famosos resultados de apli- cações das novas tecnologias da informação, nas comunicações, como também por refletirem um cenário com aparência de ficção científica neste ano de 2000 . É o início de um novo século de digitalização total que já está sendo vivenciado, no qual os átomos componentes da matéria estão sendo substituídos por bits 0 e 1 , na maior interatividade dos meios eletrônicos, permitindo transmitir simultaneamente imagens, sons, textos e animações, numa curiosa equivalência entre ensino a distância e ensino presencial (ou seja, de distância zero!).

Agora, face ao uso de tanta tecnologia avançada, surge um desafio muito natural aos educadores para fazer chegar aos alunos (seres humanos), dos quatro cantos do mundo, os conhecimentos a serem transmitidos pelo ser humano Professor.

Qual a metodologia a ser utilizada para garantir o diálogo ou o calor humano que deve coexistir na relação Professor-Aluno?

No caso, por exemplo, de uma Universidade Virtual, é necessário não se descuidar da formação integral e humanística do jovem estudante que pretende profissionalizar-se e que seja competente em sua especialidade, bem como atuante na sociedade em que vive. Caso contrário, prevalecerá um pseudo-relacionamento usual do tipo empresa.com que, certamente, o encaminhará para uma deseducação virtual. 
É imprescindível, pois, que se encontre um espaço no próprio ciberespaço (aquele mesmo espaço que em outras épocas era chamado de ondas hertzianas, utilizadas pelo rádio, televisão, computador etc.), que possa patrocinar a interação Professor-Aluno (hoje denominada humanware), local onde se manteriam diálogos vis-a-vis, entre Professor e aluno, via Web, sem perder a dimensão humana do solene ato de educar.

Dessa maneira, por mais sofisticados e evoluídos que sejam os meios utilizados para transmissão de conhecimentos e quaisquer que sejam os suportes (Escola Convencional ou Escola Virtual), o Professor continuará sendo a fonte de emulação da conduta e da operacionalidade do sistema educacional vigente.

\section{FORMAÇÃO PARA A VIDA}

Ainda dentro do tema Ser Professor, tenho um dever de gratidão aos Professores que me honraram com suas aulas na antiga e nobilíssima Faculdade de Filosofia, Ciências e Letras. Essa Faculdade, tão abrangente em seu nome, ensejou em 1934 a fundação da própria Universidade de São Paulo - hoje um dos maiores patrimônios culturais das Américas, mais conhecida pela sigla USP -, propiciando, inclusive, naquela época, a vinda de uma elite de Professores estrangeiros dos grandes centros universitários europeus.

Vencidos mais de quarenta anos das minhas licenciaturas em Física e Matemática, pela Faculdade de Filosofia, Ciências e Letras da Universidade de São Paulo, alargo meu pensamento aos ilustres mestres: matemáticos (Luigi Fantappié e Giacomo Albanese, italianos; Omar Catunda e Cândido da Silva Dias, brasi- leiros) e físicos (Gleb Wataghin e Giuseppe Occhialini, italianos; Mário Schemberg e Abraão de Moraes, brasileiros). Todos eles portadores de uma invejável bagagem cultural nas áreas das $\mathrm{Ci}$ ências, Humanidades e Artes, tal como já se exprimia, em 1490, Leonardo da Vinci - um dos mais versáteis talentos da humanidade em pintura, escultura, física, engenharia e biologia: "A Arte é um instrumento de conhecimento científico."

Lembro-me, a esse respeito, do prazer que tive em poder ouvir e ver, na Seç̧ão de Letras, o lírico poeta do mundo Giuseppe Ungaretti; sem ser seu aluno direto, desfrutava, contudo, de suas enlevadas e mágicas aulas, usufruindo uma das vantagens de ser aluno da Faculdade de Filosofia, Ciências e Letras da USP.

Elejo a década de 60 o período dos anos mais dourados de minha vida, como um apaixonado Professor que passaria a transmitir suas aulas por escrito, pois apliquei todos os saberes adquiridos na USP como escritor de livros didáticos de Matemática, convidado que fui pela Companhia Editora Nacional, de São Paulo, à qual presto a minha homenagem, neste momento, pelos longos anos de convívio intelectivo em prol do aperfeiçoamento do livro didático brasileiro, que já se apresentava com destaque na literatura mundial.

\begin{tabular}{c}
\hline Daí com a Matemática Moderna, \\
empolgando os estudiosos da \\
época, foi possível dar minha \\
colaboração numa emocionante \\
aceitação dos livros por todo o \\
Brasil e em alguns países da \\
América do Sul.
\end{tabular}


Em 1961 foi fundado, em São Paulo, o Grupo de Estudos do Ensino da Matemática - GEEM que, reunindo mestres da Universidade de São Paulo, Universidade Católica e Universidade Mackenzie, em convênio com o MEC e Secretarias de Educação do Estado e do Município de São Paulo, ofereceu cursos de aperfeiçoamento em Matemática para milhares de professores do ensino, hoje, fundamental e médio. Muitos GEEMs, então, se espalharam pelo país, numa demonstração inequívoca de uma nova dimensão na reestruturação e aperfeiçoamento da formação do Professor de Matemática.

Grandes transformações se deram no país, a partir de 1968, no campo pedagógico da Matemática: a participação nas Feiras de Ciênciàs, a criação das Olimpíadas de Matemática, a introdução de Jogos Lógicos nas Escolas, o desenvolvimento de Cursos de Matemática Moderna para os pais constituíram-se na maior mobilização de estudantes de todas as idades em torno dessa disciplina.

\section{NA ECA: BENJAMIM DA USP}

Em 1969, a convite do Prof. Dr. Antônio Guimarães Ferri, então diretor da Escola de Comunicações Culturais da Universidade de São Paulo, passei a integrar o corpo docente dessa Escola que era a benjamim da USP e representava, na época, um desafio aos educadores pelo ecletismo de suas ofertas universitárias.

$\mathrm{Na}$ reforma universitária desse mesmo ano, a Escola de Comunicações Culturais passou a chamar-se Escola de Comunicações e Artes, atualmente conhecida por um nome muito breve mas de muito orgulho: ECA. Nessa reforma, foram criadas as Artes (plásticas, cênicas e música), com a continuidade dos demais Departamentos (Jornalismo e Editoração, Biblioteconomia e Documentação, Relações Públicas, Propaganda, Publicidade e Turismo, Cinema, Rádio e Televisão) e mais a Escola de Arte Dramática.

A nova estruturação da ECA possibilitou-me introduzir no curso de graduação a disciplina Teoria da Informação que, pela primeira vez entre nós, permitiu medir, em bits, a quantidade de informação provinda de qualquer fonte geradora de mensagens (textos impressos, jornais, livros, revistas, cartazes, quadros, uma sinfonia de Beethoven, um painel de cotação de bolsas etc.). Foi uma revolução na época com a revelação do talento de muitos alunos para os aspectos quantitativos $d a$ Informação, ouvindo e calculando em bits, justo eles, mais acostumados aos estudos qualitativos da Informação nos seus aspectos sociológicos, antropológicos, históricos e filosóficos.

Como diretor do Departamento de Ensino da Fundação Padre Anchieta Centro Paulista de Rádio e TV Educativa - , tive a oportunidade de coordenar telecursos e telescolas considerados precursores no Brasil e ser autor de projetos teleducativos de projeção internacional, que fizeram jus a inúmeros prêmios.

$\mathrm{Na}$ década de 80, acompanhando o ritmo acelerado das Novas Tecnologias da Informação na Comunicação, iniciei na pós-graduação da ECA as disciplinas Cibernética e Cibernética Pedagógica, que se constituíram de grande valia para os interessados em pesquisas científicas na carreira acadêmica universitária. 
Aproveitando, ainda, o poder da informação nas telecomunicações do atual mundo globalizado, dirigi estudos na pósgraduação da ECA, a partir de 1998, de Aplicações das Redes Neurais Artificiais nos Sistemas de Comunicação, constituindo-se, no momento, numa valiosa contribuição à Educação.

Embora aposentado, sinto-me, presentemente, sempre renovado nas minhas funções de Professor da ECA, principalmente quando em contato com o ambiente de sala de aula e, mais ainda, quando estou com o pátrio poder de estar

Somos o que somos em função

do que aprendemos e do que nos lembramos. orientando mestrandos e doutorandos que representam o porvir cultural de nosso País.

Por uma verdade de consciência, sintome no dever de considerar a Universidade de São Paulo como o maior pólo de produção científica, humanística, artística e de prestação de serviços à comunidade do Hemisfério Sul. A USP acaba de inaugurar o seu sistema on-line de Informação e Comunicação, ou seja, o seu Portal para o mundo, sob a coordenação de ilustres colegas da ECA.

À Escola de Comunicações e Artes - a nossa querida ECA -, por tudo o que já fez e está propiciando aos jovens do Brasil e a muitos do Exterior, em termos de cultura geral nas dimensões sociais, humanas, científicas e artísticas, ofereço a minha admiração, dedicação e eterna gratidão.

\section{(A Mathematics professor at ECA)}

Abstract. The text is the speech delivered by Professor Dr. Osvaldo Sangiorgi during the public ceremony in which he received the title of Emeritus Professor of the School of Communications and Arts (ECA-USP). In his speech, Sangiorgi emphasized the role the Professor has in giving the student a humanistic background, most especially nowadays, a period in history in which new technologies give people unlimited access to information and in which education, distance, and the so-called virtual schools are gaining space. The Emeritus Professor also highlights the importance his professors - from the old College of Philosophy, Sciences and Letters had in his background and brings up his professional trajectory as a Professor, Mathematics textbook writer and researcher.

Key words: Professor, humanistic background,

Mathematics, Cybernetics, virtual
Palavras-chave: Professor, formação humanística, Matemática, Cibernética, virtual 